\title{
LA ESCRITURA "EN ANDALUZ" EN TRES PERIÓDICOS DEL XIX: EL TÍO TREMENDA $(1814,1823)$, EL ANTI-TREMENDA (1820) Y EL TÍO CLARÍN (1864-1871)
}

\section{Lola Pons Rodríguez}

Los políticos e ilustrados del XIX encontraron en el periodismo el medio de extender sus convicciones. La crítica ya ha insistido suficientemente en la idea de una prensapúlpito, tribuna decimonónica desde la que se podía convencer al lector con la efectividad de que en otro tiempo había gozado el estrado eclesiástico ${ }^{1}$. Las particulares circunstancias históricas de la España de principios del XIX -Guerra de la Independencia, regreso del "deseado" Fernando VII, oscilación entre absolutismo y liberalismo...- fueron, además, acicate para que nuestra producción periodística creciese, si bien no en calidad. A resultas de esto, nace todo un repertorio de periódicos, de efímera vida en su mayoría, fuertemente politizados en torno a los dos polos claves en la política española de entonces: las ideologías absolutista y liberal. Ése es el caso de dos de las publicaciones que aquí nos proponemos analizar: El Tío Tremenda (1814 y 1823) y El Anti-Tremenda (1820). Evidentemente enfrentados entre sí, en ambos concurre un mismo propósito: convencer mediante la palabra de lo razonable y legítimo de sus ideas.

El Tío Tremenda y, por herencia, su oponente El Anti-Tremenda, escogen el diálogo como cauce genérico más provechoso para inclinar al auditorio hacia su terreno: varios personajes discuten entre sí sobre asuntos políticos y sociales representando cada uno un punto de vista diferente. Estos diálogos están redactados (sobre todo el Tremenda) en un lenguaje que podríamos calificar, reconociendo todas las dificultades del término, como "andaluz", esto es, desean reflejar en la escritura la realidad fonética andaluza, con intenciones y resultados disímiles. Claro que, ese calificativo de "andaluz" sería muy discutible, puesto que los rasgos representados se sitúan más en la ladera del español avulgarado. No obstante, resulta llamativo ese uso en las grafías por dos razones: en primer lugar, por el tono de ambas publicaciones, de bastante virulencia ideológica y densos conceptos políticos, lo que de entrada parece excluir el empleo de un lenguaje popular o

\footnotetext{
${ }^{1}$ De ahí que la oratoria y el periodismo sean para algunos los dos géneros "mediáticos" que van a luchar en efectividad durante el XIX. Como se ha puesto de manifiesto: "frente a la oratoria sagrada que hasta entonces ostentaba casi el monopolio de la palabra pública, se alza ahora la prensa, que alimenta las conversaciones políticas en plazas y cafés". (Fuentes, Fernández, 1997, pg 55)
} 
castizo; en segundo lugar, por lo inédito de esa técnica en fecha tan temprana, lo que coloca a estos periódicos entre las primeras manifestaciones intencionadamente escritas en "andaluz".

Diferente formato, propósito y contenido posee el tercer periódico que vamos a analizar: El Tío Clarín (1864-1871). Publicado en fecha posterior, El Tío Clarín únicamente comparte con los dos anteriores su ocasional empleo del andaluz. Se trata de una publicación político-satírica de contenido ecléctico y tono humorístico que combina anécdotas sobre temas varios, de actualidad en la época. Es en el relato de algunas de esas anécdotas -en forma de diálogo, cuento o incluso composición en verso- donde el autor decide escribir en ese "pseudo-andaluz" literario.

La "escritura en andaluz", definida por el reflejo en el texto escrito y con los límites que impone la ortografía académica, de la realidad fonética andaluza, no suponía una novedad en el XIX, aunque sí para el gran público lector del que gozaba la prensa del momento. Los primeros textos de estas características datan, según José Mondéjar ${ }^{2}$, del siglo XVII ; sin embargo, Manuel Ariza $^{3}$ niega que en las obras propuestas por Mondéjar haya una utilización del dialecto andaluz, y piensa que es La Infancia de Jesu Christo de Gaspar Fernández y Ávila, del siglo XVIII, el primer texto literario con intencionada voluntad de reproducir en la escritura algunos fenómenos fonéticos andaluces. Lo cierto es que admitamos una fecha u otra, aquellas manifestaciones fueron más bien marginales, puesto que aparecen hablando en andaluz -o en ese "pseudo andaluz" literario- sólo algunos de los personajes de las obras. Y, aunque hay un granado repertorio de testimonios posteriores González del Castillo, Ramón de la Cruz- se suele coincidir en que hasta la Colección de cantes flamencos de Antonio Machado y Álvarez, Demófilo, no existió una decidida representación gráfica de la modalidad lingüística andaluza. Como recuerda Ariza, "fue Machado el primero que estableció unas reglas ortográficas para escribir en andaluz"4. El "especial y libérrimo uso de la ortografía" -en otras palabras, un inventario polimorfo de grafías que no siempre remiten a la realidad, y que no reflejan todos los rasgos lingüísticosque Demófilo y Rodríguez Marín declararon haber utilizado será el preferido a partir de ellos por la gran mayoría de los vocacionales escritores de andaluz: Martínez Álvarez de Sotomayor, los hermanos Machado en sus obras teatrales y, sobre todo, los hermanos Álvarez Quintero. Parece que, hasta el momento, no se ha reseñado el empleo del "andaluz escrito" en los textos periodísticos que ahora analizamos, todos ellos anteriores a la Colección de Demófilo.

\footnotetext{
${ }^{2}$ Mondéjar (1991) pg. 143.

${ }^{3}$ Ariza (1994, pg 68). En este artículo, M. Ariza revisa los textos conocidos en que voluntariamente se ha pretendido "escribir en andaluz".

${ }^{4}$ Ariza, op.cit., pg 65.
} 
El artificio lingüístico es rasgo común a todos estos textos "en andaluz"5. Volcar la pronunciación andaluza en los ajustados moldes de la ortografía normativa -la ortografía española es más foneticista que la de otros idiomas ${ }^{6}$ pero al fin y al cabo no es transcripción fonética- es empresa censurable por dos razones: las incoherencias lingüísticas en que se incurre y la falsedad que sobre un dialecto se puede difundir. Los hermanos Álvarez Quintero -máximos representantes de este género de "escritura en andaluz"-contribuyeron a propagar esta imagen deforme y avulgarada de nuestras hablas. Optaron por reflejar parcialmente la rica diversidad del andaluz, contaminándola de vulgarismos de extensión panhispánica y de no pocas falsedades fonéticas -el ceceo en posición implosiva es especialmente llamativo- y léxicas -con tan mala fortuna que muchas de esas palabras han llegado desde el Vocabulario andaluz de Alcalá Venceslada para arraigarse en nuestro diccionario académico. Estos periódicos del XIX tampoco pudieron eludir el artificio lingüístico cuando quisieron escribir en andaluz: en los casos del Tremenda y el AntiTremenda podemos hablar, más que de rasgos andaluces, de meros vulgarismos fonéticos y de un tono coloquial con el que se pretende reflejar la oralidad parcialmente, sin distanciarse demasiado de los mandatos académicos ${ }^{7}$. El Tío Clarín muestra, por su parte, un catálogo más vasto y osado de rasgos fonéticos andaluces, aunque, evidentemente, no puede escapar a la arbitrariedad y a los dislates propios de este tipo de escritura afortunadamente ya poco practicada. Su elección del andaluz es más "lógica", habida cuenta de que se destina al fin último del periódico: divertir, entretener... pero más asombroso resulta el recurso al andaluz en dos publicaciones del tipo del Tremenda y el Anti-Tremenda.

En definitiva, El Tío Tremenda, El Anti-Tremenda y El Tío Clarín pretendieron, con fines diferentes, "escribir en andaluz" una parte o la totalidad de sus páginas impresas; a continuación examinaremos qué rasgos quisieron representar y qué medios emplearon para ello ${ }^{8}$.

\footnotetext{
${ }^{5}$ Mondéjar y Rafael Jiménez han realizado estudios más detallados sobre el "andalucismo lingüístico" de las obras teatrales de Antonio y Manuel Machado y de los hermanos Álvarez Quintero, respectivamente. Cito con detalle en la bibliografía.

${ }^{6}$ Así lo ha puesto de relieve Fernando Lázaro Carreter, quien opina que nuestra ortografía es el fruto de la convivencia de dos criterios irreconciliables: el etimológico (en virtud del cual se mantienen haches y se diferencian b y v) y el "fonetista" (que redujo grupos cultos).

7 "se escribe en dialecto bien porque se trata de literatura popular -muchas veces anónima-, bien porque se trata de reflejar el habla de la gente de baja condición social o gente del campo (muchas veces por comicidad). Pero, al mismo tiempo, se procura, consciente o inconscientemente, no apartarse demasiado de la norma culta ortográfica normativa (..) lo que podría dificultar la lectura" (Ariza, op.cit. pg.77).

${ }^{8}$ Estudiaremos la lengua de los ejemplares que de estos tres periódicos se conservan en la Hemeroteca Municipal de Sevilla: El Tío Tremenda (números 71 a 100, correspondientes a 1814, y números 2 a 11, correspondientes a 1823), El Anti-Tremenda (números 1 a 5, de 1820) y El Tío Clarín (1864-1871, con los cambios de nombre y de lugar de edición que registró durante su publicación).
} 


\section{El Tío Tremenda y El Anti-Tremenda.}

Ambas publicaciones son hijas de un momento político crispado: las luchas entre absolutistas o "serviles" y liberales durante el reinado de Fernando VII. Como ya hemos dicho, escogen el vehículo de la ficción dialogada para convencer a la manera socrática. Podría parecer que la elección de una forma lingüística intencionadamente popular e incluso rústica es un camino errático para lograr tal fin, puesto que no se ajusta al preceptivo decoro aristotélico. Pero todo se explica mejor si atendemos a las circunstancias sociales del momento y a la naturaleza de una prensa aún joven en esos primeros años del XIX, que busca el favor de un sector popular al que aún no había llegado.

Ya los ilustrados habían percibido la utilidad del periodismo como medio de acercamiento a los ciudadanos, en el XVIII "el papel asignado a la prensa tiene, pues, una evidente carga pedagógica e indoctrinadora; puente de dirección única entre los ciudadanos y el poder ilustrado, su cometido principal ha de ser instruir a los lectores y persuadirlos"9. No obstante, el famoso "pánico de Floridablanca" a la llegada a España de ideas revolucionarias francesas supuso un freno en la producción periodística, que decreció en número, sobre todo en la capital. Pero el levantamiento antifrancés de 1808 va a provocar una interesante pugna de opiniones que lucharán en el terreno de la letra mediante los impresos periódicos. Se pretenderá convencer al público, a una masa popular que había demostrado su capacidad luchando contra las fuerzas de Napoleón ante la mirada impávida de la monarquía exiliada. A esta situación de magnificación del pueblo puede responder el nacimiento de un periódico como El Tío Tremenda, oscilante entre las intenciones de educar a la masa en la ideología absolutista y de halagar sus pasados arranques; testimonio, en fin, de las dos vertientes periodísticas de principios del XIX: la pedagógica, de raigambre ilustrada, y la política, llegada desde una situación convulsa como el fin de una guerra y el restablecimiento de un gobierno con un rey que aún suponía una incógnita, pese a los loores con que fue recibido.

El Tío Tremenda ${ }^{10}$ defiende los intereses monárquicos y la ideología absolutista: se felicita por el restablecimiento de la Inquisición:

"anque se icia generalmente que la Inquisicion, que la Inquisicion; como estabamos tambien entendios generalmente que su mercé habia fallecio, no toos querían creer lo mesmo que estaban viendo. Cate uste la primerita pregunta que me jizo un sugeto, à lo qual yo le contesté: No Señor, no ha fallecio: le dieron alla en Caiz un golpe con ánimo verdadero de matarla; pero con un parchecito aqui, con otro allí, con un escritito hoy, con una consulta

\footnotetext{
${ }^{9}$ Fuentes (1997) pg 23.

${ }^{10}$ El Tío Tremenda ó los críticos del malecón es un periódico de formato en octavo y, por lo general, con números de escasa longitud - cuatro páginas, esto es, medio pliego, fue su extensión habitual- Fue redactado por el absolutista José María Ríos -que luego se hizo carlista- desde 1812. Vieron la luz en la "imprenta de Padrino" según reza en los propios periódicos, y "en la imprenta de doña María del Carmen Padrino" los de 1820. Seoane informa de una publicación del mismo autor posterior a esta fecha: La Tía Norica "periódico (...) remitido desde Madrid por su autor desde agosto de 1814 hasta mayo de 1815" (Seoane, pg.58).
} 
mañana, ha dio conservandose jasta que por fin los Sevillanos han lograo plantarla en la calle güena y sana, robusta y con ganas de trabajar" (numero 71),

"tal sera la Costitucion quando no jace güenas migas con la Inquisición"

Duda de las retractaciones que muchos liberales publicaron para escapar a la represión, critica a los defensores de los argumentos liberales:

"hay dos clases de estos engañaores: unos son hombres instruios y de carrera literaria: otros son unos salvages aforraos en lo mesmo, que à manera de los loros, repiten lo que aprendieron" (99)

"los liberales son unos libertinos, hombres sin vergüenza, como lo han manifestao en sus escritos; y que lo que buscaban y querian en sus nuevas instituciones, y baxo el pretesto de reformas era, trastornarlo too, y dar en tierra con el altar y el trono" (74)

Y se expresa con la libertad que da saberse representante de la ideología en el poder:

"Necesario es carecer aun de la mas ligera vislumbre de razon para no conocer la protección y el empeño con que Dios ha mirao por la España. Salimos de franceses; de liberales; de Costitución; de nuevas instituciones, y de reformas jacobinas; y no tenemos otra cosa en que pensar que en dar à Dios gracias, y en celebrar à nuestro Rey" (74)

En efecto, Fernando VII, que llega a España con un discurso conciliador y liberal, pronto cambia su postura, apoyado por el fervor popular -es aclamado allí donde va y tratado como un representante divino- y con el sustento que brindaba el Manifiesto de los Persas. Anula la Constitución de 1812 y todas las reformas emprendidas por las Cortes de Cádiz, restablece la Inquisición y vuelve, en fin, a los viejos paradigmas de poder. El Tío Tremenda es el particular incensario en Sevilla del absolutismo de Fernando VII y, por su gran popularidad, suscitó reacciones y adhesiones igualmente apasionadas. Hay que recordar que la capital hispalense, frente a Cádiz, se había distinguido por el predominio de las tendencias antirreformistas; el único periódico de ideología liberal en la época fue Sevilla libre, y, según confiesa el Tremenda, fue éste la espuela que lo animó a escribir:

"La multitud de papeles incendiarios, subversivos y sediciosos que se publicaban en Cádiz en la época de nuestra opresión, y la casualidad de que el primero que leyó Sevilla en el día de su libertad fue el intitulado Sevilla libre, me excitaron à escribir contra este y contra todos los de su especie que llegaran à mis manos"11

En 1823 se vuelve a publicar de nuevo El Tío Tremenda, pero las circunstancias eran ya distintas: el pronunciamiento de Riego había obligado al rey a jurar la Constitución y a aceptar las decisiones de las Cortes; alarmado, el monarca recurre a sus aliados europeos, que restablecen el absolutismo en nuestro país: es el comienzo de la Década Ominosa. Tremenda dirá en uno de los últimos números aparecidos:

\footnotetext{
${ }^{11}$ Num 79 pg 325. Este número está escrito totalmente según la ortografía académica.
} 


\begin{abstract}
"la libertad de imprenta y las reuniones patrióticas no servian de otra cosa que de sembrar la zizaña entre todas las clases del estado. Acusaciones, desvergüenzas, calumnias, ridiculeces, indecencias, apodos; en esto se ocupaban las prensas y este era el entretenimiento de los necios oradores en sus tribunas".
\end{abstract}

El último número de esta segunda serie que comentamos apareció cuando ya Fernando VII iba a retomar el poder absoluto. Como veremos, estas dos etapas presentan diferencias en el lenguaje y en el tratamiento de los contenidos; a esto hay que sumar otra divergencia más: ya El Anti-Tremenda durante el Trienio liberal había lanzado sus dardos contra la publicación absolutista - el propósito de agravio es evidente desde el propio título- , por lo que los diálogos del Tremenda en esa segunda serie van a ir encaminados hacia la defensa propia más que hacia la glorificación del monarca.

Los personajes se repiten en ambas series: Lorenzo Campillo, apodado el Tío Tremenda; Castaña -el interlocutor más habitual de Tremenda-, Epidemia -un analfabeto $^{12}$-, Paco -apodado Cascarón- y Anastasio-motejado Podrío-. Peñasco y Cuca son gitanos, sólo aparecen en un número ${ }^{13}$. Los apodos y la familiaridad con la que se tratan entre ellos presentan la tertulia como un lugar de ambiente distendido y amistoso. Tremenda da nombre al periódico, ya que es el personaje principal, y aparece en la mayoría de los diálogos. Su voz representa la cordura y sabiduría que posee el pueblo por naturaleza. Poco sabemos de él: es agricultor ${ }^{14}$ y su mujer Norica le secunda en fervor monárquico. Su carácter es reflexivo, acentuado progresivamente en los últimos números de la serie de 1814, aunque no duda en insultar a los liberales cuando se ofrece la ocasión, llegando su discurso a ser achulado ante las recriminaciones de los partidarios de las reformas. A pesar de ello, es el más comedido de los personajes, quizá porque, pese a su incultura, demuestra conocer toda clase de términos políticos e incluso jurídicos (hace referencias a fueros medievales, remite literalmente a leyes otorgadas por el rey..) Y es que en el discurso de Tremenda el autor oscila entre aproximarse a la expresión popular y coloquial del pueblo, remedando sus giros y locuciones más castizas, y derramar los sustentos teóricos e históricos que él cree fundamentales de la ideología absolutista. Consecuencia de esta vacilación es la inadecuación expresión-contenido que domina en todos los números: no es lo mismo utilizar el "andaluz escrito" para transcribir coplas flamencas de naturaleza oral -Machado y Álvarez- o para pintar cuadros de costumbres y

\footnotetext{
${ }^{12}$ Como queda claro cuando, a la hora de firmar una carta de apoyo al monarca, Epidemia dice: “yo también jaré mi cruz, porque no sé firmar, pero à fé que usté se lo arvertirá asina à S.M" (76).

${ }^{13}$ Así, dice Cuca: "Miste quantisimos españoles se convirtieron en fuelles vivos, en fuelles de Satanás! pero nunca veria uste à un Gitano en tan maldecia comision! Miste quantisimos probes caian toitos los dias en la trena por causa de los afrancesaos! Miste quantisimos infelices morian à soplos como candil! Miste quantisimos esertores hubo de las banderas de la patria! Pero mi gente, siempre fiel y leal hasta la grímpola! Buscando su via honraamente!".No se puede decir, por tanto, que todos los contertulios sean gitanos; tampoco hay diferencias lingüísticas entre los dos gitanos y el resto; por otra parte, la práctica inexistencia de gitanismos excluye que El Tío Tremenda esté "escrito en caló" (Aguilar, 1988, pg.257).

${ }^{14}$ De esto nos informa en el número 97 el personaje de Cascarón: "No viene su mercé esta tarde; pero no es por naa de eso: pasé esta mañana por su casa, y me lo encontré à la puerta aparejando el borriquillo paa largarse à la era" (pg.397)
} 
de argumento idealizado - hermanos Quintero, Machado- que emplear tan ficticio vehículo de expresión para hablar de constituciones o conspiraciones catilinarias.

En esos números de El Tío Tremenda podemos registrar los siguientes rasgos lingüísticos:

1. Pérdida de -d-: se produce no sólo en participios -ado, -ido, sino también en otros contextos (sufijo agentivo -dor, terminaciones -dero, -udo, -dura y otros entornos fónicos de naturaleza no forzosamente sufijal): señalaos, mentao, entendios, tenio; achocaura, verdaera, alreedor, prevaricaor, suor, Caiz, preicar, comunidaes.... la pérdida afecta también al grupo -dr-: Pae Pericaor, Mairí (Madrid, con vocalización). Cuando la caida de -d- provoca el contacto de dos vocales iguales, el autor parece preferir la representación gráfica sin fusión: toos, caa (cada), ponderaa, ciudaanos, preparaa, moo (modo), ustees. La caída de - d- es el rasgo más frecuente en el Tremenda, si bien desde los primeros números observamos que no es fenómeno sistemático. Ahora bien, ejemplos como alrededor que en los primeros números son meros descuidos, hay que interpretarlos de manera diferente conforme avanza la publicación: a partir del número ochenta se multiplican en número, lo que parece coincidir con una intencionada voluntad del autor de "castellanizar" ortográficamente parte de su texto. No obstante, este sometimiento a la norma no será total y seguirán apareciendo formas con d intervocálica perdida.

2-Pérdida de d-: en posición inicial es intensa la pérdida de /d/, en el verbo decir (ice, iciendo, iga), en palabras que poseen el prefijo des- (escubierto, espegaba, esgañitando, esmentirme) y en otros contextos (etenerse, ifunta, ). En algunos casos, cabe pensar en una probable deformación intencionada sin correspondencia con la pronunciación real: seiciosa, ispusimos, espídome de vos, itamen, ecente (sediciosa, dispusimos, despídome de vos,dictamen, decente). En la preposición de, la caída (tras é la mosca, rebentando é cólera) alterna con la conservación.

3-Pérdida de - d: en posición final la - d desaparece, aunque no es un rasgo constante: vecindá, mitá, igualdá, libertá, lealtá, voluntá, mercé, salú. Más sistemática es la pérdida en la forma usté. Hallamos también ejemplos del tipo: faciliaa, utiliaa, singulariaa, vaniaa (facilidad, utilidad, singularidad, vanidad) que no creemos sean testimonio de abertura vocálica sino meros cruces con formas con-d-perdida y vocales sin fusionar, como las que vimos anteriormente: preparaa, caa...

4-Aspiración de f-: la articulación aspirada de la f-inicial latina o de aspirada árabe (jasta) está testimoniada profusamente en El Tío Tremenda: jizo, jecho, jablan, jambre, jundía, jocico, juyendo, jumo, jedía, jornilla, jaces de leña, e incluso jermosa (documentado en varios números, junto con hermoso, hermosa), ajogao, zajurda...

5-Trueque de labial b y velar g: güelta, güena, golviendo, gufonaas (bufonadas), agüelo, guñolillos (buñuelillos), güespees..

6-Rotacismo: arma que alterna con alma.

7-Metátesis de líquidas: trempanito, probe, catreal (catedral), hiproquitas, hiproquesia... 
8-Reducción de grupos cultos: costitución, asinación, perfetamente, circuspeto, istruciones, manifico, descricion; e incluso vocalización del grupo -kt-: proyeuto, en efeuto (formas muy habituales), conceuto, afeuto.

9-Vacilación en las átonas: mesmo, prenosticaba, escrebir, sigún.

10-Otros vulgarismos: dimoño, arreparar, armitir, anque, muncho, cudiao, semos, pos, paece, dende (por desde), ha dio, mos (por nos: mos ha dexao), asina...

Realmente, podríamos calificar de vulgarismos casi la totalidad de los fenómenos presentados hasta aquí, puesto que la mayor parte de ellos no puede adscribirse exclusivamente a Andalucía -otros sí, como la aspiración de f-. Estos vulgarismos tienen la finalidad de caracterizar la altura social de los personajes, pero en virtud de ellos cualquiera de los dialogantes podría ser considerado hablante de otra modalidad de español peninsular, puesto que se trata en su mayoría de incorrecciones panhispánicas. Esto ocurre porque los rasgos típicamente andaluces: aspiración de s implosiva, y, en el área sevillana, seseo/ceceo y yeísmo no fueron representados por el autor de El Tío Tremenda para caracterizar "el tosco lenguage" de los contertulios del Malecón. Si rastreamos en los ejemplares de este periódico podemos encontrar testimonios polimórficos de seseo y ceceo pero parece que responden a la inadvertencia del autor o a su desconocimiento ortográfico, más que a la intencionada presentación de la oralidad: lancesillo (por lancecillo, en el número 74), sapato (número 95), y, en la segunda serie, disen (en boca de Tremenda en el número 4), capitalisaciones y cosina (número 11). Nos tropezamos también con ejemplos del tipo: aquello de que está rebozando el corazón, refleccionar, reflecciones.

Hay otros rasgos andaluces manifiestos en la morfología y el léxico. Así, el empleo de chico por "pequeño" ("no es posible que un hombre en el exercicio de su razon, conciba el plan de un mundo sin pobres, sin criaos, sin chicos, sin inferiores (número 87). Los diminutivos preferidos son -ito e -illo: trempanito, palabritas, solito, funcioncita, chiquetita, toito (hay un caso de toiticos), cosilla, manecillas... los ejemplos son muchos y parece que -ito sobrepasa ligeramente a -illo.

Salvo en los vulgarismos señalados ya, lo que hallamos es un general respeto por la ortografía académica vigente en el momento: la de 1763 para los ejemplares de 1814 y la de 1815 para los periódicos de 1823 . Así el contraste quando/cuando en unos y otros números manifiesta una de las modernizaciones que estableció la Ortografía de 1815; asimismo, la escritura de exâmen, auxîlios, mâximas -con acento circunflejo para indicar pronunciación /ks/- y el empleo de diéresis en casos como freqüentes. Hay algunas faltas ortográficas entre las páginas de El Tío Tremenda: "reusando", "rebentando", "ubas", "embíen", "hecharía" y alguna otra. Pero, por lo general, no se deforma arbitrariamente la escritura para reforzar el dialectalismo.

Conforme salen a la luz nuevos números de El Tío Tremenda, van desapareciendo de ellos las formas más avulgaradas. El número 79 de la primera serie es una auténtica declaración de intenciones del editor sobre el contenido, la intención y la lengua de El Tío Tremenda. Se trata de un ejemplar escrito completamente en español estándar, que se inicia con una frase cercana a la palinodia: "Parece llegado el caso de que cese este periódico, ó 
por lo menos que se corrija su estilo", pero el autor aclara más adelante que no se trata de enmendar tan peculiar forma de expresión sino que "se completarán los Números correspondientes à los meses que faltan, siguiendo el estilo familiar y jocoso que hasta aqui; pero corregido el lenguage de aquellas voces que afean su pureza", esto es, se continuará como en los números anteriores pero disminuyendo el componente de escarnio y las voces ofensivas. Pero sin duda lo más interesante del número es la exposición del editor acerca de los propósitos que le movieron a confeccionar un periódico de tales características:

"Al pueblo, pues, en su clase ínfima me propuse sostener desde el momento, y para conseguirlo adopté la idea que me ocurrió de hablarle en su tosco y propio lenguage. La rapidez con que se extendió este papel prueba lo bien que se recibió por el pueblo (...) Para conseguir mejor el fin que me propuse, he usado de las armas mismas de nuestros contrarios, esto es, de la burla, la sátira y el desprecio (...) Es indudable que mas sensacion é impresion causa en el pueblo baxo la burla y el ridículo, que los más sólidos y eloqüentes discursos".

Aun reconociendo que El Tío Tremenda no es "papel comparable con el Procurador General, la Estafeta, la Atalaya y otros" (todos ellos periódicos absolutistas coetáneos), el editor justifica su trabajo como un deber social que viene cumpliendo desde 1810, "primero contra los franceses, aunque rodeado y oprimido de ellos, y despues contra sus apoderados los reformadores". Reconoce que ya no hay lugar para seguir combatiendo esas ideas, por lo que anuncia que al acabar el año, cumplido el compromiso con los suscriptores, finalizará la publicación del Tremenda. Sin que suponga un corte radical esta declaración, sí se advierte que, a partir del número 81 , la presencia de la ortografía normativa es más habitual, y, si bien siguen apareciendo vulgarismos de toda índole, va a ser menos frecuente la aspiración de f inicial y la caída de - d final. En los números anteriores, Tremenda no mostraba una especial superioridad lingüística respecto a los demás, pero ahora va a quedar claro que su habla es diferente a la de sus rústicos interlocutores. Así, en el número 99 se pone de manifiesto el menor grado de instrucción de Castaña:

“Castaña: (...) Era Currillo el Cigüeño.

Tremenda: Gran salvage! De los ilustraos à la moa. Porqué no lo echó usté paa acá? (...) Me atrevo à apostar que trataba de materias científicas.

Castaña: Qué sé yo si eran lentíficas o no lentíficas, lo que le pueo asegurar (...)"

Los ejemplares que aquí hemos venido denominando "segunda serie", correspondientes a 1823, descubren muchas más diferencias entre los personajes:los parlamentos de Tremenda aparecen escritos según las normas académicas, este personaje prescinde además de las expresiones coloquiales que tan frecuentes eran anteriormente. El vulgarismo es paulatinamente menos intenso -hasta llegar casi a la inexistencia- y se reduce a las intervenciones de Epidemia, Podrío, Cascarón o Castaña.

El autor de El Tío Tremenda se propone representar en la escritura la oralidad, la espontaneidad y "el tosco lenguage"con que se expresaban los componentes de las clases populares. La alteración ortográfica para reproducir la fonética no es el único vehículo 
expresivo, también se recurre a toda clase de refranes, giros coloquiales de aliento castizo e interjecciones a fin de lograr "la burla y el ridículo". Así, una idea que juzgan desacertada suscita la exclamación de "voto a brios"; "la puse de güelta y media" dice uno acerca de la Constitución; cuando un contertulio falta al encuentro, se le echa en cara "güena rabona hemos jecho"; del mismo modo, cuando alguno se va de la tertulia sin poder contar lo que quería, se "lleva en el buche lo que traía preparao"; son los liberales quienes más vehemencia comunicativa provocan: "mal dimoño le de la muerte", sus discursos son remedados como "patatin patatan”, "churriburri”... se exclama en una ocasión "¿no han querio sus mercees libertá de imprenta? pos que la mamen"; de las reclamaciones liberales se dice que suponen un continuo dale que le darás, y vayan puñales y vengan rejones; para denostar los conceptos de libertad e igualdad pregonados por los liberales se afirma que "quando un Alcalde de un pequeño lugar es un Juan Lanas y un saco de paja, no hay cosa con cosa en el pueblo"; se cuenta que, si hay igualdad, no habrá justicia para castigar al pillo que le "endiñe" a uno "dos docenas de bofetaas", y es que oir a los liberales "es una vendimia", al menos, según el editor, que los llama "zopencos, palurdos y salvages" entre otras lindezas; de un cardenal que durante el Trienio ha favorecido a los liberales se afirma que "ha servido de instrumento de imbecilidad"; a los franceses se les llama "gabachos" e "invisibles" "porque nadie los puee ver". De una función celebrada en Sevilla el 16 de junio de 1814 en homenaje a un nuncio del Papa se dice en tono encomiástico "jvaliente función estuvo!"; una sentencia juiciosa y razonable es "una verda de à folio"; sobre las retractaciones liberales, tan usuales en la época, se advierte que hay que ser precavidos "no sea que nos den gato por liebre y sea peor lo roto que lo escosío". No obstante, Tremenda se muestra clemente con los "arrepentidos" y prefiere el perdón a la represión puesto que "mas tierra se aelanta con el sombrero que con la espaa" aunque la clemencia no es, desde luego, lingüística, ya que se les profieren flores como: "vaya usté con mil pares de cuernos". Quien no tiene estudios, conoce sólo la "gramática parda". Tremenda cuenta que cuando va a los toros increpa a los picadores diciéndoles "collonazos y cobardones"; son expresiones repetidas persistentemente en el texto ¡naranjas!, ;cachiporra!, ;canario!, ¿chitón!, jea!', ¡tate!, ¡vamos!. El repertorio de coloquialismos es interminable, y no es ahora el momento de analizarlo; bástenos insistir en que refuerzan el carácter de traslación de lo oral que el editor pretende desde un principio con idea de atrapar al lector inculto en las páginas de su diario.

Este mismo empeño (sostener al pueblo en su clase ínfima con su "propio y tosco lenguage") mueve a la escritura al redactor o redactores del Anti-Tremenda ${ }^{15}$. Se proponía combatir con sus mismas armas al popular Tío Tremenda, que volvió de nuevo a publicarse en 1820: el vehículo del diálogo, la discusión entre personajes, la facilidad del contenido, la expresión "castiza"... instrumentos todos ellos al servicio del liberalismo. Pese a que el

\footnotetext{
${ }^{15}$ Tertulia del Malecón o El Anti-Tremenda. Se guardan cinco números de 1820 en la Hemeroteca Municipal de Sevilla; son ejemplares en octavo, pero de mayor número de páginas que El Tío Tremenda. Se vendía a seis cuartos el ejemplar normal, a nueve cuartos el suplemento -se publicó uno, adición al número 2, titulado Oración gástrico biliosa que entre pucheros y furores dijo el Dr. Silvestre Pancharra...- y a un real el ejemplar doble; se imprimía en la Imprenta de Puerta (calle Arinas -sic- num.6).
} 
título nos podría hacer pensar que todo el Anti-Tremenda se destinaba a increpar a la publicación absolutista anterior, lo cierto es que sólo se hace mención al Tremenda en contadas ocasiones. El redactor prefiere demostrar lo equivocado de los argumentos antirreformistas antes que ocuparse continuamente de insultar al Tremenda. El personaje de Trancazo, que representa el comedimiento y la moderación propia de un liberal -su voz nos suena a alter ego del autor-, dice que tal periódico "solo merece el desprecio", y que lo perdona. Pero la discreción liberal no es tan pródiga: el redactor no se resiste en un momento dado a denostar al Tremenda, y lo hace mediante el personaje del Amolador, en el número 3, significativoamente titulado El rigor de las desdichas. Pariole adrede su madre y ojala no le pariera. El Amolador dirá:

"El Tremenda supuesto bien puede ser pequeñito; pero es una víbora ponzoñosa, capaz de envenenar á miles. Dios nos libre á todos de sus maliciosas mordeduras. Aun á soplos quisiera matar á ciertos sugetos.(...) El Tremenda es escritor maligno, de dañada intención, enemigo del projimo, de la Constitucion, y de todos sus partidarios. (...) El Anti-Tremenda es un Patriota harto conocido por sus principios, y saben muchas personas de autoridad, que en tiempos peligrosos no dejó de esparcir la luz en cuanto estuvo en sus alcances (...) esa ojeriza y encarnizamiento contra el Anti no tiene otro origen que ser este amigo de la Constitucion y de la libertad de su patria; y el otro enemigo de ambas" 16

Pese a las discrepancias ideológicas, es natural pensar que el Anti debe mucho al Tremenda. El redactor del Anti se reconoce deudor del Tremenda en cuanto al medio de acceso a "la plebe": Y es que ambos periódicos se arrogaron la misión de cumplir con un "deber social": educar al pueblo en un ideario correcto. Ya lo vimos en el Tremenda, que así lo declaraba en una de sus páginas. El Anti-Tremenda lo anuncia desde el encabezamiento inicial: todos los números aparecen presididos por el lema horaciano "lectorem delectando, pariterque monendo"17, incidiendo desde el principio en ese propósito de enseñar a los iletrados a la vez que los divertía. La intención es la misma, la técnica también. Sólo utilizando sus mismas armas podrá combatirlo entre quienes más acogida tuvo. Según confiesa el editor:

"El título de Anti-Tremenda era oportunisimo en las actuales circunstancias, porque el papel del tremenda corrio con aceptacion entre la plebe, y era conveniente que otro papel, siguiendo la misma forma de tertulia, pero sin seguir su lenguage tan corrompido, se hiciese lugar entre las mismas clases de gentes, y fuese poco à poco inspirando en ellas opiniones diametralmente opuestas á las que esparcio el antiguo Tremenda. Este pensamiento debio ser aprobado por cierta clase de criticos, que no conocen deben circular papeles escritos en diversos estilos, para que cada clase de ciudadanos elija o preñera el que se acomoda más á

\footnotetext{
${ }^{16}$ Pgs. 30-33.

${ }^{17}$ Salvo el suplemento, que presenta una disposición diferente a la habitual en el periódico; aun así, ostenta una divisa no menos reveladora: "Quid, si vox libera non sit, liberum est? ¿Hay libertad donde no se puede hablar? (Persio)”.
} 
sus alcances y conocimientos. No todos los papeles son para todos; y el Anti jamas tuvo la loca presuncion de escribir para los sabios"18

No obstante esa coincidencia en el propósito, el desarrollo formal de ambos periódicos fue diferente. En El Tío Tremenda todos los interlocutores compartían el ideario absolutista y sólo destacaba Tremenda del grupo por su papel de "conductor" de la tertulia y, más tarde, por una caracterización más culta, aun sin extraerlo el redactor de su estrato popular. En El Anti-Tremenda los personajes que dialogan -Fray Cornelio, Periquillo Fernández, don Trancazo, Zampabollos, Aleluya, don Restituto...- tienen diferentes puntos de vista: hay curas de pensamiento antirreformista, jóvenes despiertos de creencias liberales, analfabetos que por todo preguntan y a los que hay que adoctrinar... es decir, hay una heterogeneidad en cuanto a los estratos sociales dibujados y en cuanto a la diversidad de pensamientos que en esta publicación se representan ${ }^{19}$.

Si en El Tío Tremenda todo el periódico quería reflejar el lenguaje de las clases más populares, el Anti-Tremenda reserva este registro únicamente a uno de sus personajes: Zampabollos, que aparece sólo en los dos primeros números. Sus intervenciones no dan para mucho; sus preguntas y castizas exclamaciones (caa mochuelo á su olivo, mamar la breva) son muy cortas, aunque de ellas podemos extraer los siguientes rasgos lingüísticos:

1-Caída de -d-intervocálica: queo, lucio; hay también ejemplos de vocalización: paire.

2-Caída de d-inicial: igo, ice.

3-Caída de -d en posición final de palabra: usté, verdá, paterniá.

4-Aspiración de f- inicial latina: jablan, jará, jablarme, jartando.

5-Trueque de b por g seguido de diptongo -ue, por equivalencia acústica: guen, gueno.

6-Rotacismo: frayle por freyre.

7-Otros vulgarismos: leamos usté (léanos usted).

\footnotetext{
${ }^{18}$ Núm.5; pg.51.

${ }^{19}$ Para definirlos nos puede servir la propia descripción que ofrece El Anti-Tremenda en su número 2. Don Restituto reprocha a Trancazo que alterne en su tertulia con "idiotas": "Periquillo, joven de muy pocos años, es un valiente tronera, aunque no le faltan luces; Aleluya es un pobrete; Zampabollos un bestia, que cuando abre la boca, rebuzna; y el reverendo Cornelio es un frayle muy preocupado, por no decir botarate". Hemos de observar que el uso del adjetivo "preocupado" remite aquí a una acepción diferente a la actual, aludía a una excesiva y ciega devoción religiosa, cerrada a la admisión de nuevas ideas enriquecedoras. El significado se confirma en la frase que pronuncia don Trancazo en la alocución dinal del número 4: "Busquemos hombres comprometidos y decididos por nuestra causa; hombres impertubables é inflexibles en sus opiniones; activos y laboriosos; amigos del estudio y de la sabiduría; despreocupados, y al mismo tiempo religiosos; enemigos de la opresión y el despotismo y llenos de virtudes políticas". Para Gil Novales (1975, vol.2, pg.980) en el "vocabulario políticosocial de 1820-1823" una "preocupación" era un "prejuicio", por lo que "preocupado" equivalía a "con prejuicios, o sea, antiliberales".
} 
Curiosamente, son todos vulgarismos que también reflejaba el Tremenda, y el Anti no innova en ninguno -no sesea ni cecea ${ }^{20}$, no da muestras de yeísmo-. Pensamos que esto ocurre porque el redactor del Anti no había leído otra ortografía "fonética" que la de su antecesor y adversario, por lo que no era capaz de "imaginar" otros quebrantamientos de la norma ortográfica.

Los parlamentos de los otros contertulios se escriben según la ortografía académica, y, aunque entre ellos haya discrepancias políticas, van a compartir un estilo "correcto". El propio redactor del Anti se sintió obligado a justificar estas "transgresiones" de Zampabollos, que, ciertamente, lo ataban a la tradición del Tremenda que él quería denostar:

"El Anti no ha seguido en eso [en el lenguaje], como tampoco en las opiniones, las huellas del Tremenda; y lejos de eso, dijo en otro tiempo á este, que la monotonia de aquel lenguage bárbaro era fastidiosa; que solo servia a corromper el idioma patrio; y que, cuando mas seria tolerable una sola persona que hablase asi; pero no todas. Conforme a este dictamen, solo habla en su Tertulia de ese modo Zampabollos, y lo que habla es muy poco; y a pesar de esta moderacion se le desterró enteramente de la tertulia en los núm. 3 y 4 ,21

Las preocupaciones lingüísticas del Anti-Tremenda no se quedan aquí. El número 5 se dedica a contestar al Argos, un periódico sevillano ${ }^{22}$ que lo había acusado en sus páginas de utilizar un lenguaje impropio. El Anti se defiende con algunos de los argumentos que hemos podido leer hasta aquí, añadiendo toda una serie de ataques a la lengua empleada por el Argos. Resulta de ello un interesante discurso sobre corrección sintáctica y estilística, fundado en la consideración de que quien imita "el lenguage de los payos" ofende menos a la corrección que quien habla con pretensión de ser culto pero se expresa mal:

"Pues un escritor asi contribuye mas á la corrupcion del lenguage, que el que por gracejo ó extravagancia imita el de los payos: porque aun la gente mas vulgar é idiota no habla de ese modo, y sabe que siendo aquello una burleta no debe imitarse. Pero el que escribe con seriedad habla magistralmente, y decide en todas materias en tono de oraculo, es escuchado como tal, y los hombres superficialmente instruidos adoptan involuntariamente muchas locuciones ó modos de hablar que beben en charcos cenagosos" 23

A Trancazo el discurso del Argos le parece "lánguido y pajoso", pero decide ceñirse, según sus palabras, a las locuciones defectuosas que en el periódico aparecen. En efecto, las expresiones que critica son realmente incorrectas:

\footnotetext{
${ }^{20}$ Bien es cierto que podemos toparnos con hipercorrecciones (inucitada, expreciones) que "descubren" el seseo del redactor o incluso hay claras muestras (masetilla); pero, si no hay conciencia y voluntad de representar ese rasgo del andaluz, sólo podemos situar tales ejemplos en el terreno del error ortográfico (como versas).

${ }^{21}$ Número 5, pg.51.

${ }^{22}$ Se trata de El Argos o Revisor Andaluz, diario de ideología absolutista que se publicó en Sevilla desde mayo de 1820.

${ }^{23} \mathrm{pg} .51$.
} 
- el redactor del Argos dice que no se le disimula algo. A esto responde el Anti: "No se nos oculta querria decir su merced, ó no negaremos, ó no disimularemos.." ya que la expresión utilizada le parece "locucion gringa, redundante y sin sentido";

- se censura el uso de que en vez de porque en la frase: No que el pueblo español necesite de mucho estímulo;

- en la oración $Y$ entre nosotros mayormente cuando el monarca mismo, el Anti encuentra un hipérbaton: "Con decir: $Y$ mayormente entre nosotros estaba todo compuesto, porque recae, ó apela, como dicen los Dialécticos, sobre el nosotros, y no sobre las palabras siguientes: cuando el Monarca mismo. Puesto del otro modo deja dudoso sobre quien recae, y ms no habiendo coma despues del adverbio".

- se critica el empleo de "cálidas" por "acaloradas" en la construcción cálidas imaginaciones: "Calido es el ojo, es el pimiento, y otras muchas cosas. La imaginación, la fantasía, los hombres se acaloran";

- El Anti-Tremenda se ríe del giro usado por el Argos "echar expresiones": "Vaya una frase bonita y de nuevo cuño";

- Se reprueban las muestras de "dequeísmo" deslizadas entre las páginas del Argos. Dice el Anti: "Nos ha sorprehendido por un lado de que se nos recuerde un nombre \&c. Aquel de está demas, porque el nominativo de la oracion nos ha sorprehendido por un lado es la oracion siguiente. (...) No es esta la unica vez que usa con igual falta de sintaxis de la proposicion de."

- se critica también la acuñación del adjetivo "enlatinadas", que el Anti califica de "voz bárbara ó macarronica".

Hay alguna otra crítica pero la obviaremos para no extendernos demasiado. Es realmente curioso este alegato en favor de la corrección del idioma, que demuestra cómo el Anti se sirvió de los vulgarismos de Zampabollos sin demasiada confianza en que fueran útiles, por ello los suprimió de su periódico. Pero tampoco le gustaban las expresiones foráneas y la inserción de vocablos o giros insólitos en el idioma español. Fray Cornelio, un fraile de convicciones antirreformistas que aparece en los diálogos del Anti-Tremenda, dirá de esos defectos del Argos:

"esos son defectos veniales, nacidos acaso de que ese Señor haya viciado algo su idioma patrio viajando por Paris ó por Londres"24

\section{El Tío Clarín.}

Como hemos visto, El Tío Tremenda y El Anti-Tremenda intentaron reflejar en sus páginas el lenguaje popular y castizo. Trataron de "escribir el andaluz", pero con un resultado pobre, no sólo porque -ya lo hemos dicho- la grafía es un impedimento para ese tipo de transcripciones, sino también porque únicamente escogieron un limitado repertorio 
de rasgos, vulgares todos ellos y presentes en su mayoría en la totalidad del dominio hispánico, lo que convierte esos supuestos parlamentos en andaluz en una mentira lingüística. La intensidad en el uso de esa escritura es diferente en cada periódico: en el Anti-Tremenda, su empleo es muy tímido, porque el redactor no quiere caer en la impropiedad: sólo un personaje se expresa en ese registro, y ese personaje es eliminado ya en el tercer número. Como hemos visto por los ataques que dirigió al Argos, el autor de El Anti-Tremenda era consciente de la importancia de la corrección estilística y gramatical, y de los riesgos que podía suponer la impropiedad lingüística. El Tremenda, por su parte, pretende estar escrito en su totalidad en ese registro popular, con el que se quiere hacer reir al lector y convencerlo de las bondades de Fernando VII.

La idea de que la pronunciación andaluza favorece la risa, por ser un modo de hablar ocurrente o gracioso, no era nueva en el siglo XIX. Tal como investigó MaaTeresa García Godoy, los parlamentarios de las Cortes de Cádiz que se expresaban en andaluz, y, en especial, los que ceceaban, provocaban la carcajada general ${ }^{25}$.Esta valoración fue aprovechada especialmente por el Tremenda, pero quien va a sacar del andaluz más partido cómico será El Tío Clarín ${ }^{26}$. Así lo imponía el propio carácter de la publicación. Una idea del contenido ecléctico, divertido y deslenguado de este periódico la ofrece su primer ejemplar:

"este periódico, compuesto de sustancias salitrosas y epigramáticas, es un antídoto infalible contra la melancolía; destruye los malos humores y fortifica aun los espíritus más pobres y apocados (...) EL TIO CLARIN sabe demasiado que su índole de mordaz, satírico y tenaz perseverancia en meterse con todo el mundo, le proporcionará el que más de un ridículo se le persone con humos de espadachín y duelista; pero se apresura à prevenir á estos, para bien de sus costillas, que aunque él no entiende una palabra de achaques de esgrima, posee un garrote perfectamente acondicionado y con una correita en el puño para asegurarselo mejor

\footnotetext{
${ }^{25}$ Para García Godoy (1997, pg 511), "la valoración del andaluz como forma de hablar graciosa no sólo se encuentra generalizada en la España de 1800, sino que, además, se conoce en la España ultramarina". Aporta además dos testimonios donde se intenta "transcribir el andaluz": un texto de Mesonero Romanos y un periódico satírico de 1813 (La Campana del Lugar) que critica a los absolutistas pintándolos como ceceantes en uno de sus números

${ }^{26}$ El Tío Clarín, periódico satírico político. Su primer número se publicó el lunes 4 de enero de 1864 . Se conservan números en la Hemeroteca Municipal de Sevilla hasta 1871. Como "editores responsables" figuran, según las épocas, Luis Mariani, González y Santigosa. El 19 de agosto de 1867 se interrumpe su publicación, y aparece el 8 de septiembre de 1867 con el título de La Campana. Edición semanal satírica . El 27 de enero de 1868 vuelve a aparecer El Tío Clarín, que desde el 3 de diciembre de 1871 se edita desde Madrid. Tal y como se anuncia al final de primer número, el periódico es de aparición semanal: "Se publicará todos los lunes, empezando por el primero del año 1864, en un pliego de papel español con buenos tipos; conteniendo artículos satíricos originales, cuentos, chistes, estravagancias, chascarrillos, epígramas y gacetillas, resumiendo todo lo mas interesante y divertido que se publique en los periódicos, tanto nacionales como estrangeros, artículos de sana moral, anuncios, etc". El periódico se vendía a cuatro reales. El cambio de título se debió con toda probabilidad a la acción de la censura, según deja ver el "campanero mayor" en el primer número: "Hijos mios; esta Campana que acabamos de estrenar, espreciso tocarla con mucha prudencia si no queremos verla cascada á las primeras de cambio, dadas las condiciones atmosféricas en que nos encontramos. Si la conservamos, nos ha de producir muy buenos cuartos el día que hagamos con ella lo que hizo Mendizabal con sus ilustres antecesoras".
} 
á la muñeca, el que desde hoy estará de manifiesto en sus oficinas para el que guste inspeccionarlo"

El "clarín" es la trompeta con la que el editor denuncia todo lo censurable y se mofa de todo lo risible de la España de su tiempo, desde el político que pacta según su conveniencia, la crisis económica que sufre el ciudadano medio o la epidemia de cólera que pasa por la capital andaluza, hasta la existencia de un bache en una céntrica calle sevillana o el último invento que se va a mostrar en la Exposición de París. El "tío Clarín" aparece en el periódico como un crítico personaje, hábil en el manejo de la sátira y valiente a la hora de clamar con el sonido de su clarín para poner sobre aviso de una situación. Litografías que pintan escenas curiosas, diálogos pintorescos, breves sentencias cargadas de intencionalidad, pasatiempos que juegan con nombres de políticos para reprobar sus conductas... los medios de burla son innumerables. Esa "ensalada" de temas y técnicas va a incluir también el aspecto lingüístico, manifiesto en algunos artículos.

El periódico está en su mayor parte escrito según la ortografía estándar. Pero el redactor del Clarín en ocasiones refleja en la escritura los rasgos fonéticos meridionales, también otras modalidades lingüísticas-asturiano, gallego- de las que no nos ocuparemos aquí, pero cabe señalar que cuando aparecen, se destinan únicamente a suscitar la hilaridad y a alimentar los tópicos que hacen a sus hablantes gente inocente y simple ${ }^{27}$.

A veces el supuesto "andaluz" es motivo de escarnio, en otras ocasiones las frases en andaluz son tratadas como auténticas sentencias senequistas. Los propósitos al representar el andaluz son muchos y dispares, por lo que resulta complicado elucidar qué conciencia lingüística habita detrás de esos textos, llenos de contradicciones aparentes. No obstante, en nuestro análisis hemos podido detectar dos valoraciones distintas de la oralidad de los personajes:

a) Valoración positiva: el reflejo escrito del andaluz, sin excesiva carga de vulgarismos, no es en sí considerado risible. En el texto sirve para representar con todo la verosimilitud posible:

- la voz sabia y juiciosa del pueblo llano,

- y, en menos ocasiones, el desparpajo de tipos costumbristas como la gitana o el majo;

\footnotetext{
${ }^{27}$ No nos extenderemos analizando la representación de estas dos modalidades lingüísticas. El gallego es representado por algunos rasgos fonéticos, léxicos y morfológicos -éstos escasísimos- insertos en parlamentos de construcción mayoritariamente castellana: el meu amu me ha mandadu.(...) ha habido una fanfuriña de todos los demus (número 2). El asturiano es caracterizado por la palatalización de 1- y arcaísmos como la conservación de f-: las cuentas se las ajusté yo á ellos, pues coji un garrote, é si non fuyen por esa calle abaiso lles hubiera dao sarna que rascar" . Este fragmento se extrae del número 142 (15 de octubre de 1866) y aparece en boca de Jacinto, un criado del tío Clarín ("El tío Clarín, queridos lectores, es viejo y comienza a estar achacoso, su vista y su oido se han debilitado y sus piernas no corresponden con sus deseos de andar (...) por estos y otros motivos (...) ha tenido a bien aumentar sus gastos (..) con un famulo. Este famulo es una alhaja rara". Posteriormente, el tío Clarín lo califica de bruto y dice que podría ser mostrado en público atado a un pesebre. Otros textos en este fingido "asturiano" se encuentran en los números del 16 de enero de 1871 ("Las cosas de Fermín") y 1 de mayo del mismo año ("Trompetazos").
} 
b) Valoración negativa: el reflejo escrito del habla vulgar andaluza, por el contrario, se censura y reprueba. Como veremos no son ya textos con rasgos andaluces, sino vulgares.

a) Entre los textos con valoración positiva, la escritura del andaluz -a través de bastantes fenómenos lingüísticos desde la aspiración de $\mathrm{F}$ al seseo y al ceceo- puede servir para dibujar a personajes despiertos - gitanas, chulos- o de una sensatez cercana a la de Tremenda y Trancazo en El Tío Tremenda y el Anti -es el filón senequista al que nos referíamos antes-. Se explota así el "andaluz" para lograr mayores dosis de verismo o de ambientación costumbrista. En estos cuadros será muy escaso el recurso al vulgarismo, por lo que podemos concluir que el autor -hablante él mismo de la variante lingüística andaluza en su modalidad sevillana- era complaciente en esa reproducción gráfica del andaluz y no quiso "contaminarla" de impropiedades. El andaluz también será empleado en este sentido para "transcribir", quince años antes que Demófilo, unas agudas y muy peculiares "coplas flamencas":

\section{“CANCIÓN GITANA}

(Música de la caña con acompañamiento de guitarra)

Ya llegó la hora/ la horilla yegó / de que tá partes é la vera mía/ sin apelasion/ Te fistes de mi vera/ sigue tú tu rumbo/ que ya veras compañero mío/ que pronto me jundo"

\section{EL MISMO AL MISMO}

\section{(Música del punto de la Habana)}

Aunque vayas y te bañes / en el gorfo de León / no te has é quitá la mancha / que conmigo te cayó/ en tus Ríos me bañé / me engalané con tus Rosas / y ahora me dejas chabó / con siete palmos de trompa". 28

Los rasgos que registramos como caracterizadores del "andaluz" empleados por el redactor del Tío Clarín son:

1- alteraciones de /d/, mucho menos frecuentes que en el Tremenda. La caída de - dintervocálica es ocasional y asistemática: deos, inventao, peirle, pae, compare, tó, ruean. Registramos muestras de caída de d-inicial: ecirme, igo, así como caída de -d final: usté, verdá.

2- pérdida de consonantes finales: levantá, serví, menesté, quitá, rafaé

3- vacilación en el timbre de las átonas: siguro;

4- apócopes del tipo "pa";

5- trueque de b y g: guelvan los ejemplos son escasísimos;

6- aspiración de f: jermoso (una gitana, num 170), jace, ajorcarla;

7- rotacismo: gorfo, er mundo, argo, sirbíos, arcanfó, farta;

\footnotetext{
${ }^{28}$ Número 115.9 de abril de 1886.
} 
8- seseo: los ejemplos se incrementan conforme avanza la publicación: moso, grasia, munisipal, sierta, cabesa, apelasion, contribusion, pestaso. No obstante, está muy lejos de ser sistemático, puesto que incluso en los textos donde hay seseo de detectan ejemplos como: fuerza e flaquesa; se puede deber a "seceo" o, lo que es más probable a incoherencia del redactor;

9- ceceo: aparece en muy contadas ocasiones. En el número 186 dirá un gitano: ezo lo zé yo tocar mejor.

10- yeísmo: se documenta raramente, y, cuando aparece, es muy curioso comprobar alternancias del tipo: la horilla yegó; o bien Seviya, ayí junto a "aquella", "allí (número 17). En el ejemplar correspondiente al 13 de marzo de 1871, un diálogo entre una mujer y un político que acude a su casa en busca de votos, arroja fenómenos de variación muy curiosos: "-¿Esta ahí su caballero esposo?" a lo que responde la mujer "aquí no hay ningún cabayero";

11- aspiración de -s: el autor sólo la refleja en dos casos: "vamos ja ve" (vamos a ver), ma jayá é la presiensia (115: más allá de la presidencia);

12- simplificación de grupos cultos: sulevao;

13- metátesis de líquidas: presonal;

14- vulgarismos: he dio, asina, antier, arsoluto, pacencia, semos, alevanten, no seasté, doquin, fistes (fuiste).

En cuanto a la morfología, hallamos el uso de forma pronominal en tercera persona con verbo referido a un vosotros y conjugado en segunda persona; se testimonia en el número 113, cuando "el andaluz" le dice a dos nazarenos que especulaban sobre la posibilidad de que alguien los reconociera: "Anque se vistais de Pae-terno -jugando además con el significado de "terno"- os conose to er mundo"

En el léxico, encontramos "candela" por "lumbre" según es propio del andaluz occidental:

"saqué un pitillo, le deshice la cabecilla y tocando suavemente en el brazo á mi vecina le dije: -Moza buena, ¿me hace Vd. el favor de la candela ${ }^{29 ،}$

Claro que el redactor no era consciente de la adscripción andaluza de este uso. Sí era sabedor de la diferencia que el verbo "chocar" presentaba en su empleo en Sevilla y en Madrid: en dos ocasiones recuerda que "chocar" significa en Madrid "llamar la atención":

\footnotetext{
${ }^{29}$ Número 184, del 5 de agosto de 1867. Ya aparece como andaluz en el Diccionario de Autoridades (1726-1739): "candela se llama también (y se usa mucho en Andalucía y en otras partes) la misma brasa de la lumbre: y assi suelen decir, Deme un poco de candela, Trahigan candela.". Véase también el mapa 713 del ALEA.
} 
"CHOCAR en Madrid es hacer gracia una cosa, llamar la atención otra. En Sevilla CHOCAR es reventarle á uno una cosa, pegar tres patadas en la boca del estómago, ó cosas por el estilo,"30

También hallamos gitanismos como jindama o chabó. Otros ejemplos no se deben ya a la mano del redactor sino a algunos lectores que enviaban sus composiciones y cuentos para que fuesen publicados: bato para "padre" en el "Cuento de costumbres" remitido por Francisco Lara y Ruiz en el número 19, y gaché, chorré, moza juncá en la "Canción" enviada por José Velázquez y Sánchez.

b) La valoración negativa del otro género de textos no se refiere al andaluz sino a la presencia de rasgos vulgares. Al autor parece molestarle sobremanera la incorrección lingüística y el vulgarismo, se emplearán a menudo los registros escritos de la oralidad para sustentar ataques satíricos crudelísimos contra quienes son chabacanos o toscos en su habla. El tío Clarín lanzará sus invectivas contra aquellos en cuya expresión abunde el vulgarismo, la impropiedad, o contra quienes cometan en la escritura faltas ortográficas.

Así en el número 31, bajo el lema "Modelo de directoras", encontramos la siguiente comunicación:

"El TIO CLARIN recomienda al señor inspector de instrucción pública una señora directora de esta capital, que al reprender á sus discípulas, les dirije los siguientes apóstrofes: niñas, si no susestais mu quietas, me enrritareis la sangre. El idioma castellano estropeado nos demanda justicia,"31

Pero sin duda el texto más ilustrativo en este sentido -y también uno de los más divertidos del periódico- es el que aparece en el número 5 bajo el título de "CERTAMEN". Se trata de una larga composición en octosílabos donde se satiriza sobre ese "castellano estropeado" ofreciéndose el tío Clarín a premiar a quien más incorrecciones cometa:

"(...) en cabildo celebrado al efecto consiguiente, varios premios ha acordado, bajo la forma siguiente: Primero: aquel aspirante que con mayor lucimiento diga estáuta, morumento estógamo, comendante ú otro análogo esperpento, sobre todo opositor tendrá mérito sobrado para alcanzar el honor de que sea clasificado caballería mayor.

(...) Cuarto: el que diga espital diga Improstura, Seomo, esparda, niervo, endispuesto o idéntico desatino.

simenterio ó catredal ganará un lote compuesto de una cincha y un bozal. Quinto: Optará con ventaja al regalo estraordinario de dos raciones de paja, quien dijere urnia, miajaa, espetáculo o impresario. (...)Octavo: Por mulo romo se tendrá en grado supino, al que haciéndose latino, Noveno: al que con jactancia diga estenasa, enclusive Bilbado ó Paris de rancia se le pegará el quien vive á dos pasos de distancia. (...) Once: Al que diga ofesina, pantasma, haiga, sanajoria porchinela ó pantomima desde luego se destina á dar vueltas á una noria.(...)

\footnotetext{
${ }^{30}$ Anotación a la Sección "Trompetazos" del número 173 (20 de mayo de 1867). El 10 de diciembre de 1871, en un ejemplar ya publicado en Madrid, se vuelve a insistir en esta divergencia semántica.

${ }^{31}$ Ejemplar del 1 de agosto de 1864. La negrita es nuestra.
} 
La burla, compuesta según el clásico motivo del "elogio de lo vituperable", muestra cómo la visión que del pueblo tenía el redactor de El Tío Clarín, era contradictoria. Resulta una auténtica paradoja que en ocasiones se glorifique al pueblo como portavoz de opiniones sabias y juiciosas en esos textos que hemos llamado de "valoración positiva"y otras veces se les satirice en estos desenvueltos fragmentos que ahora comentamos, por su vulgaridad e impericia ortográfica. Una suscriptora envía al periódico una sátira contra las charadas que habitualmente inserta en sus páginas El loro. La misiva está plagada de faltas:

“(...) Muy Señor mio, agradeseré a V. incerte en su diario la siguiente solusion á la charada del numero del lunes ó sea elde ayer. se lo estimará mucho su afegtisima serbidora y sucritora. Luisa M. Puede V. ermendarla si no le parese bien.
Me carga demasiado
ber tus charradas lorito,
y por eso muy quedito
te diré lo que é pensado
que ni eres charadista
ni poeta ni escritor
y que de ti mucho dista
ser un buen conpocitor."

El loro será quien replique a esta iletrada "señorita" a la que llama "palurda":

\begin{abstract}
"aquello de afegtisima,ermendarlo y otras patochadas, que se leen en la epistola de Luisa M., lo mismo le caen a una señorita que a un santo un par de pistolas. Pero estas son nimiedades que no vienen al caso, por que hasta ahora ningun Papa, ni concilio general han definido que deje de ser tenida por señorita la que hable como un patan; ni sé yo de ningun articulo de la Constitución, que infelizmente nos rige, en el cual se califique de palurda á la que no sepa castellano (...) Entre otras cosas, dicen los zoilos, que ese Ver berrea como un becerro (...) Mas esto, que en un aguador nadie lo censuraría; ¿por qué se ha de motejar en una serbidora sucritora? (...) la é subrayada está llorando á lágrima viva por una h, hizo muy bien la señorita en negársela, porque el sonido lo mismo es con h que sin ella, y estando, como estamos en tiempo de economías, no hay que desperdiciar una letra siquiera.."
\end{abstract}

Como podemos comprobar, cuando El Tío Clarín refleja la oralidad oscila entre la censura a los vulgarismos y la exaltación del pueblo llano, sabio y sensato. Esos propósitos no siempre están diferenciados, y a veces es imposible adscribir un texto a una u otra intencionalidad. A ello se añade el hecho de que algunos de los textos en andaluz fueron remitidos a El Tío Clarín por suscriptores con aficiones literarias; estos textos muestran posturas distintas a la hora de caracterizar a los personajes e incluso los rasgos lingüísticos escogidos para la "escritura en andaluz" serán diferentes a los seleccionados por el redactor habitual. Así, los dos cuentos remitidos por el coriano Francisco Lara y Ruiz, e insertos en dos números de 1864 muestran, además de los rasgos ya vistos del Tío Clarín, fenómenos como el ceceo (usté lo ize), el "heheo"o aspiración de s inicial de sílaba o palabra: no jeñó y, además, exhiben una intencionada e inexplicable deformación gráfica del tipo abía, con migo, ablasla, nosvia ("nos veía"), poique,", inexistente en los textos del redactor del 
Clarín. De José Velázquez y Sánchez es la canción "La cigarrera" donde, como ya hemos visto, abunda el léxico caló.

En definitiva, el reflejo gráfico del andaluz en estos tres periódicos del XIX adolece de las mismas fallas que otros textos análogos: falsedad, avulgaramiento, ortografía deforme... si bien es cierto que cada una de las publicaciones difiere de las otras en cuanto a rasgos reflejados y conciencia lingüística. Resulta curioso este hallazgo por la temprana fecha del Tremenda y el Anti, así como por lo inédito de los rasgos del Clarín .

Hay muchas diferencias entre estas tres publicaciones: El Tío Tremenda y El AntiTremenda son periódicos políticos atados a las vicisitudes históricas de su tiempo -el turbulento e ideológicamente cambiante reinado de Fernando VII- en el que la elección de un lenguaje andaluz escrito parece encerrar claras intenciones populistas, sobre todo en el primer caso. El Tío Clarín emplea ocasionalmente la escritura en andaluz -al igual que remeda otras hablas como el asturiano o el gallego- para realzar la gracia de un cuadro crítico o poner de manifiesto la incultura de algunos componentes de la sociedad. El redactor o los redactores justificaron esa elección lingüística y asumieron las repercusiones que suponía: acercamiento didáctico al pueblo en el caso del Tremenda; para el AntiTremenda, escarmiento y ejemplo de cómo no se debía hablar y para El Tío Clarín una oportunidad más de diversión no exenta de censura.

\section{BIBLIOGRAFÍA.}

AGUILAR PIÑAL, F: "Para la historia de la prensa en Sevilla: el Redactor Sevillano", Temas sevillanos, Sevilla, Universidad de Sevilla, 1988.

ARIZA, M: "Fonética andaluza en textos escritos. Su valoración lingüística y artificio", Lingüística Española Actual, XVI/I, 1994, pgs. 59-78.

FUENTES, F.J; FERNÁNDEZ SEBASTIÁN, J: Historia del periodismo español. Prensa, política y opinión pública en la España contemporánea, Madrid, Editorial Síntesis, 1997.

GARCÍA GODOY, Mª T: "Valoración del andaluz en el Cádiz de las Cortes", El habla andaluza. Actas del I Congreso del Habla Andaluza, Sevilla, Seminario Permanente del Habla Andaluza, 1997. Pgs- 505-513.

GIL NOVALES, A: Las Sociedades Patrióticas (1820-1823). Las libertades de expresión y de reunión en el origen de los partidos políticos, Madrid, Tecnos, vols I yII, 1975.

JIMÉNEZ, R: "La pronunciación andaluza en la obra de los Álvarez Quintero”, “, El habla andaluza. Actas del I Congreso del Habla Andaluza, Sevilla, Seminario Permanente del Habla Andaluza, 1997, pgs. 575-585.

MONDÉJAR, J: "El andalucismo ambiental y el andalucismo lingüístico en el teatro de los hermanos Machado", Actas del Congreso Internacional Conmemorativo del Cincuentenario de la muerte de Antonio Machado, Sevilla, Alfar, 1990, pgs. 137-157.

----- Dialectología andaluza. Granada, 1991. 
SÁNCHEZ MANTERO, R: Fernando VII. Un reinado polémico, Madrid, Historia 16, 1996.

SEOANE, Ma C: Oratoria y periodismo en la España del siglo XIX, Valencia, Fundación Juan March/Editorial Castalia, 1977. 